\title{
Eliciting user preference for quantitative vs. emotional informa- tion display in eco-feedback designs
}

Cite this article as: Qifang Bao, Mian Mobeen Shaukat and Maria C. Yang, Eliciting user preference for quantitative vs. emotional information display in eco-feedback designs, Research in Engineering Design https://doi.org/10.1007/s00163-021-00363-y

This Author Accepted Manuscript is a PDF file of an unedited peer-reviewed manuscript that has been accepted for publication but has not been copyedited or corrected. The official version of record that is published in the journal is kept up to date and so may therefore differ from this version.

Terms of use and reuse: academic research for non-commercial purposes, see here for full terms. https://www.springer.com/aam-terms-v1 


\title{
Eliciting User Preference For Quantitative Vs. Emotional Information Display In Eco-Feedback Designs
}

\author{
Qifang Bao \\ Department of Mechanical Engineering \\ Massachusetts Institute of Technology \\ 77 Massachusetts Avenue, 3-446 \\ Cambridge, MA 02139 \\ qfbao@mit.edu \\ Mian Mobeen Shaukat \\ Department of Mechanical Engineering \\ King Fahd University of Petroleum and Minerals \\ Dhahran Saudi Arabia \\ mshaukat@kfupm.edu.sa
}

\section{Maria C. Yang}

Department of Mechanical Engineering

Massachusetts Institute of Technology

77 Massachusetts Avenue, 3-449B

Cambridge, MA 02139

mcyang@mit.edu 


\title{
Eliciting User Preference For Quantitative Vs. Emotional Information Display In Eco-Feedback Designs
}

\begin{abstract}
Eco-feedback is a design strategy that reminds users of their resource consumption as they use a product. The ultimate goal is to promote pro-environmental behaviors in users by making them aware of the environmental impact of their consumption. The way these designs present resource usage information can significantly impact user perceptions. This paper investigates two aspects of resource usage presentation, quantitative feedback and emotional evocativeness, by evaluating 32 designs spanning electricity, materials, transportation, and water via surveys of 619 university students in the US and Saudi Arabia. Both these aspects are positively correlated with perceived product appeal and perceived effectiveness in encouraging sustainable behavior. It was found that presenting quantitative resource usage information was more helpful to respondents who could better estimate resource consumption, while the emotional evocativeness of a design aided respondents with lower and higher resource consumption knowledge to a similar degree. In addition, we found that images of living creatures and strong visual cues evoked strong emotions in users, and female participants, in general, responded more strongly than males to this emotional evocativeness. These experimental findings cast light on how to better design eco-feedback products to be more widely accepted.
\end{abstract}

\section{Keywords}

Product design, User centered design, Eco-design, Sustainable product use, Emotional design 


\section{INTRODUCTION}

Eco-feedback is a design strategy that presents users with information about resource consumption or environmental impact caused by product use (Tang and Bhamra, 2008) (Froehlich et al., 2010; McCalley and Midden, 1998; Petersen et al., 2009). It is one of the product-led intervention strategies that aim to use products as a mechanism to promote proenvironmental behaviors in users (Deutz et al., 2010; Lilley et al., 2005; Sohn and Nam, 2015). Traditional eco-design techniques such as environmental life cycle assessment (Finnveden et al., 2009) and planning (Kobayashi, 2005) focus on reducing resource usage and controlling waste production during the manufacturing process (Mesa et al., 2018) and at a product's end of life (Kroll and Hanft, 1998; Rose et al., 2002). Common intervention efforts such as public campaigns (Fielding et al., 2013; Kurz et al., 2005; McKenzie-Mohr, 2000) or educational programs (Boudet et al., 2016; Staats et al., 2004) aim to influence people's environmental attitudes, increase their environmental knowledge, and further encourage sustainable behavior. Product-led intervention for sustainable behavior bridges these two approaches (Lilley, 2009) and focuses on reducing a product's environmental impact during the use phase (Bhamra et al., 2008; Rodriguez and Boks, 2005; Telenko et al., 2008; Wever et al., 2008) and facilitate consumers to make green purchasing decisions (D'Souza et al., 2007).

An example of eco-feedback is an energy monitoring system that provides feedback on household electricity usage (Ueno et al., 2006). Another example is a beverage package labeled with an anti-littering message (Wever, 2003). Both of these have been proven effective in promoting pro-environmental behaviors such as conservation of energy and reducing litter. Feedback or information on resource usage is generally believed to inspire short-term sustainable behaviors, and also increase users' longer term awareness and understanding about how everyday behaviors affect the environment (Froehlich et al., 2010). Compared to other strategies of product-led intervention designs such as "behavior steering" which 
encourages behavior change via embedded product constraints or affordances, and "smart" designs which automatically take actions to enforce behavior change, eco-feedback has the advantages of being less intrusive (Cor and Zwolinski, 2015) and relatively easy and low-cost to implement (Shu et al., 2017). However, they are effective only when users are engaged (Telenko and Seepersad, 2010) and can properly interpret the information (Järvi and Paloviita, 2007), and their user acceptance is still limited (Barreto et al., 2013). These show the urgent need to gain a better, more rigorous understanding of how to make such products appealing to users and gain wider adoption.

This study takes the perspective that successful eco-designed products need to provide environmental benefits but also need to appeal to users and customers (Karlsson and Luttropp, 2006). From a user-centered design point of view, seemingly small, but critical, details of a design can strongly impact whether a product is used effectively, whether a user's experience is satisfying (Norman, 2013), or whether a product is perceived as environmentally sustainable (Diego-Mas et al., 2016). For eco-feedback products, the way resource usage information presented is a key design concern (Fang and Hsu, 2010; Froehlich et al., 2012) and subtleties in information presentation can make significant impacts on user perceptions, such as presenting a ranking of an individual's consumption within a population versus presenting consumption relative to the population average (Aldrovandi et al., 2015). However, to date, there are few experimental studies of how different types of designs can influence users' perception of ecofeedback information.

Traditionally, resource usage information is presented quantitatively (Froehlich et al., 2012) with the expectation that rational users, who make decisions to maximize their net benefit, will behave environmentally consciously once they are made aware of the environmental consequences of their behavior. For example, some cars are equipped with fuel economy meters that present the numerical miles-per-gallon of a vehicle under the assumption that 
drivers will change their driving patterns accordingly to save fuel and reduce greenhouse gas emission. However, this assumption often fails in practice and one study suggests that quantitative information tends to be effective only on those who already have strong proenvironmental intentions (Zachrisson and Boks, 2012). In contrast, it is recognized that one's environmental concerns and beliefs can be emotionally charged (Bang et al., 2000), and emotions such as anticipated regret or guilt are linked to consumers' decision making including the selection of sustainable products (Goucher-Lambert et al., 2017) and services (Kim et al., 2013), and ecological behaviors such as recycling and use of public transportation (Carrus et al., 2008). In a prevailing notion from the area of Emotional Design, a successful product should not only have high functional performance but also deliver strong emotional value to the user (Boatwright and Cagan, 2010; Norman, 2004). Based on these, we hypothesize that an intervention design that is more emotionally engaging (Fang and Hsu, 2010) will be more appealing to users.

This study compares two key aspects of the way resource usage information can be presented in eco-feedback designs: being quantitative and being emotionally evocative, and examines how they influence user perceptions and preferences. The research questions are:

Q1: How are quantitative and emotionally evocative usage information presented in an ecofeedback design linked to users' evaluation of the design's appeal and users' perception of the design's effectiveness in encouraging sustainable behavior?

We believe both quantitative and emotionally evocative aspects of resource usage can influence user perception, and expect that designs that present more quantitative resource usage information or evoke stronger emotions will be more appealing to users and be perceived as more effective in encouraging pro-environmental behaviors.

Q2: Do users with different levels of environmental awareness or quantitative resource consumption knowledge, or with different demographic backgrounds respond differently to the 
quantitative and emotional aspects of resource usage information presented in an eco-feedback design?

Previous studies have offered evidence that users who have different levels of environmental awareness and knowledge (Cor and Zwolinski, 2015), motivations for sustainable behaviors (Srivastava and Shu, 2015), and social orientations (pro-social or pro-self) (McCalley and Midden, 2002) tend to react differently to intervention designs. Thus we consider preference heterogeneity among users, that not all people like the same designs (Feick and Higie, 1992; Windrum et al., 2009), and aim to identify design strategies specifically for different user groups.

To answer these questions, we generated four design forms of eight eco-feedback products, resulting in a total of thirty-two designs ranging from quantitative to emotionally evocative. Surveys were constructed and deployed among university students to collect feedback and evaluations of these designs. Links between the design forms and user perceptions were analyzed. In the end, implications of our findings and limitations of the study are discussed.

\section{METHODS}

A substantial literature exists on methods for evaluating user responses to product-led interventions including eco-feedback designs (Daae and Boks, 2015), such as testing immediate user reaction via surveys (Montazeri et al., 2012; Sohn and Nam, 2015), testing short-term effectiveness of promoting sustainable behavior with in-lab experiments (Cor and Zwolinski, 2015; MacDonald and She, 2013; Montazeri et al., 2012), and testing product usability and long-term behavior change effectiveness with field studies (Montazeri et al., 2013; Wever et al., 2008). Design representations such as rendered drawings (Sohn and Nam, 2015), CAD models (Goucher-Lambert and Cagan, 2015) and prototypes (MacDonald and She, 2013; Montazeri et 
al., 2013) have been used to elicit user feedback on provisional ideas of sustainable products. This study surveys potential users across a wide geographical area for their responses to a relatively large variety of designs by presenting them with sketches of the designs.

A preliminary study (Bao et al., 2016) suggested the necessity for a broader, more comprehensive study to achieve conclusive results. In this present study, four resource categories were explored, within each category two products were identified. Four design forms of each of the eight products were generated, resulting in a total of thirty-two designs. Surveys collecting design evaluations were distributed among students in five universities in two countries, with 619 valid responses. Potential links between survey respondents' preferences for specific designs to their personal characteristics, including gender, environmental awareness, and knowledge of resource consumption were examined.

\subsection{Eco-Feedback Designs}

Though many environment-related fields are worthy of study, a subset was selected that was directly linked to both the consumption of natural resources and the everyday lives of the general public: Electricity, Materials, Transportation, and Water. In addition, these categories were general enough to allow for a diverse range of products. Two products in each category were chosen: one providing dynamic feedback on resource usage and the other presenting static information that encourages a user to carry out sustainable behaviors.

Electricity:

- An Electricity Meter that monitors home electricity usage

- A Light Switch that reminds people to turn off the lights when leaving a room Materials:

- A Paper Towel Dispenser that tracks how many paper towels have been consumed

- Waste Cans that separate landfill, recyclables, and compostable waste 
Transportation:

- A Fuel Economy Meter that tracks the miles-per-gallon (MPG) of a vehicle

- A Public-Transport Poster that encourages the use of public transportation

Water:

- A Water Tap that monitors the day's cumulative water usage

- A Washing Machine with a selectable water-saving mode

These products take their inspiration from the eco-design literature and a range of industrial design examples (Arroyo et al., 2005; Cor and Zwolinski, 2015; Kuznetsov and Paulos, 2010; Montazeri, 2013; Montazeri et al., 2013; Petersen et al., 2009; Sohn and Nam, 2015), and were believed to be products that student respondents would likely be familiar with. Visual representations of four versions of each of the products were generated, taking the following forms, respectively:

- Text or Chart displays resource usage information with clear, quantitative data

- Visual Emphasis attracts users' attention through strong visual elements

- Metaphor Using Objects includes inanimate objects related to the environment or to resource consumption

- Metaphor Using Living Creatures incorporates animals or plants as reminders of the environment and resource usage

These design forms were drawn from existing literature and aimed to cover a range from quantitative to emotionally evocative. Text or Chart is a design form widely used in products such as water or energy dashboards (Agarwal and Weng, 2009; Froehlich et al., 2012). Visual emphasis draws on a basic technique in graphic design and user interface design (Galitz, 2007) to draw a user's attention to information through graphical elements. Examples include the battery icon on a mobile device, which turns red when the battery runs low. Metaphor is another common form in user interface design (Fishkin, 2004) that makes analogies between 
the design and other concepts, and has been used widely in product-led interventions (Fang and Hsu, 2010; Montazeri, 2013; Montazeri et al., 2013). Two types of Metaphors were explored: metaphor using inanimate objects, e.g. using a light bulb as an indicator of energy consumption, and metaphor using living creatures, e.g. using an image of a polar bear on a melting iceberg as a reminder of global warming. It was anticipated that images of living creatures would evoke strong emotions such as empathy for animals suffering from climate change, or hope for our ability to avoid future environmental damage (Swim and Bloodhart, 2015).

Research suggests that when presenting representations to users, differences in fidelity and style can overshadow the content of a design (Macomber and Yang, 2011). Thus these designs were hand-sketched by a single professional industrial designer to maintain a consistent visual style to mitigate potential evaluation bias (Häggman et al., 2015). Example designs are shown in Figure 1. The top left product is an electricity meter that monitors home electricity usage. Designs 1-4 are varied forms of the meter showing cumulative daily usage. The second product is a washing machine with a selectable water-saving mode. Four versions of the water-saving mode button were shown. The Supplementary Material documents details of all thirty-two designs. 


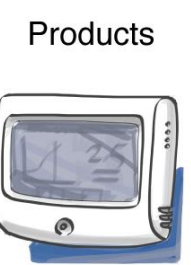

Electricity meter

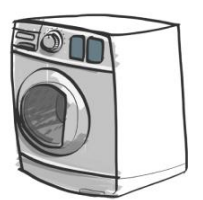

Washing machine water-saving mode
Design 1

Text or chart

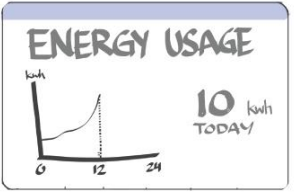

WATER SAVING

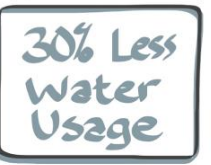

Design 2

Visual emphasis

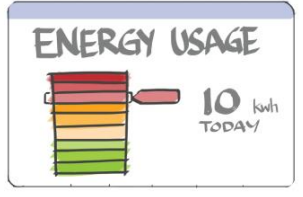

WATER SAVING

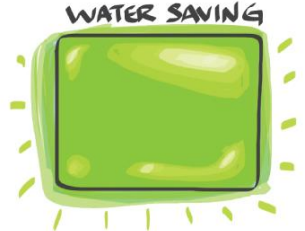

Design 3

Metaphor using objects

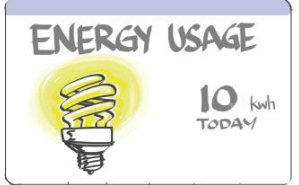

WATER SANING

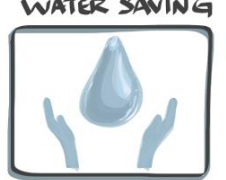

Design 4

Metaphor using living creatures
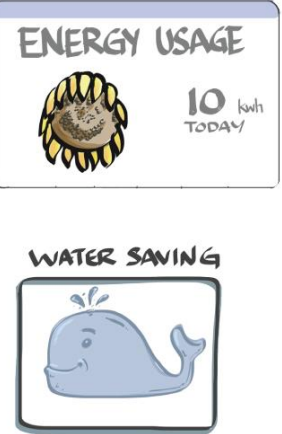

Figure 1 Example eco-feedback designs, each with four forms

\subsection{Survey Development and Implementation}

A survey was constructed to ask respondents to evaluate and provide feedback on the ecofeedback designs. In addition, the survey evaluated the respondent's ability to estimate resources used in common daily activities and their awareness of environmental sustainability. Demographics including age, gender, year of school, major, university, and nationality were collected.

In order to avoid survey fatigue by presenting respondents with all thirty-two designs in a single survey, four distinct versions of the survey were created, each focusing on one resource category. Each respondent was randomly assigned to one version of the survey and was presented with resource estimation questions and in total eight designs of two products from one resource category. The awareness questions were the same across all surveys.

An online survey platform, Qualtrics, was used to create and deploy the survey. Pilot testing was conducted with four product design graduate students for timing, wording, and reading level. Their feedback was used to refine the survey. 


\subsubsection{Survey part I: resource consumption knowledge and environmental awareness}

Respondents' knowledge of resource consumption for Electricity, Water, Materials, or Transportation was evaluated. In the Electricity and Water versions, respondents were asked to estimate the electricity or water usage in common daily activities, such as using a laptop computer for an hour (Attari et al., 2010), or running a washing machine for one cycle. In the Materials version, respondents were asked to differentiate recyclable and compostable waste from landfills. For Transportation, respondents were asked to estimate the $\mathrm{CO}_{2}$ emissions of different modes of transportation.

The usage and emission estimation questions were presented as logarithmic sliders to emphasize orders of magnitude rather than precise values. Respondents were not expected to know exact values for these activities and thus were asked to give rough estimates. To aid estimation, reference points were provided, such as the electricity consumed by a single light bulb. Respondents could choose to view the survey in either SI or Imperial units. Multiple online resources including the website of the United States Environmental Protection Agency were referred to in developing answers for these questions (see Supplementary Material for more information). For devices whose resource consumption may vary by model, brand, or working condition, standard devices with typical consumption rates were selected as the reference.

Eight questions were used to evaluate the respondents' environmental awareness: six asking the survey respondents to rate if they agreed or disagreed with statements regarding natural resources and the environment, and two asking the respondent to self-report their environmental awareness and environmental friendliness of their lifestyle on 1-5 Likert scales. These questions were adapted from the New Ecological Paradigm scale (Dunlap et al., 2000), a widely used measure of environmental concern; and the section of Attari, et al.'s Survey on Energy (Attari et al., 2016) that measures environmental attitude. 


\subsubsection{Survey part II: design evaluation questionnaire.}

The survey first presented the designs in random sequence and asked the respondents to rate them using 1-5 Likert scales on four criteria:

- Clarity: How clearly did the design show resource usage/How clearly did the design communicate the idea of encouraging sustainable behavior?

- Emotion: How strong an emotional response did the design evoke?

- Effectiveness: How effective would the design be in encouraging the respondent to behave in a more environmentally friendly way?

- Appeal: In general, how much did the respondent like the design?

These criteria and their definitions were presented in the survey. Clarity is a measurement of how individuals perceive quantitative resource usage information, while Emotion measures the overall intensity of emotions evoked by the designs. Effectiveness looks at the designs' potential influence on user-product interaction behavior as perceived by respondents. Appeal is an overall evaluation of how attractive or desirable users find a design to be. Optional openended comment areas were provided for respondents to elaborate on their ratings.

While the first two criteria directly evaluate the two aspects that are of interest in this study (quantitative vs. emotional), the latter two serve as evaluations for the perceived quality of the overall designs. These criteria are independent measurements as a user would not necessarily find a design effective or appealing even though they find it presents clear information and/or evokes strong emotion. However, we still expected the ratings to be correlated. We should note that all four criteria were subjective measurements from individual respondents, and thus variations of ratings were expected. Therefore, average ratings for each design were calculated for further analysis.

After rating each of four designs of one product, respondents were presented with all four 
designs at the same time in a randomized sequence and were asked to select one that they would choose for themselves, known as a "most preferred" choice (Luce, 2005; McFadden, 2001). These choice questions simulated consumers selecting one product out of a group of similar products, with attempts to approximate their potential purchasing/adoption decisions. In the example of the electricity meter, respondents were presented with the four electricity meter designs at the same time and were asked, "Imagine you were selecting an electricity meter for your apartment. Which one of the designs would you prefer the most?" If the product was not something individuals would purchase for themselves, they were asked to think about the product they would select for their community (e.g. their university). Based on consumer preference theory, one would choose the design that was the most desirable, all things considered (Frank and Glass, 1991). Again, optional comment areas were provided for respondents to elaborate on their responses.

The Supplementary Material documents more details and presents examples of the survey questions.

\subsubsection{Survey distribution and quality control}

The survey link was sent with a recruiting email to campus housing email lists, departmental email lists, course email lists, and relevant student clubs' email lists. Students voluntarily took the survey. US participants were provided with the chance to be entered in a lottery for Amazon gift cards of $\$ 10, \$ 20$ to $\$ 50$. The entrance into the lottery was independent of the survey responses, and thus we believe no bias was induced with the incentive. No incentives were provided to the Saudi Arabian participants.

The following screening rules were applied to ensure data quality:

- Respondents had to spend at least 5 minutes completing the survey. This minimum time was selected because it was the fastest time the researchers themselves could complete the survey while reading all questions and providing meaningful responses (Kittur et al., 
2008; Mason and Suri, 2012).

- Respondents with resource consumption knowledge scores less than 1.5 interquartile ranges below the first quartile were considered outliers and were excluded from further analysis. This rule was enacted after observing illogical responses to knowledge questions, such as using the default starting points of the slider bars as answers to all questions.

\subsection{Data Analysis}

\subsubsection{Resource consumption knowledge score and environmental awareness score}

For the Material usage questions, respondents received 1 point each time they chose the correct way of disposing of a particular type of waste, with a maximum possible score of 10 points. For the Electricity, Transportation and Water surveys, the score for each respondent's knowledge level of resource usage was calculated using the proposed equation:

$$
\text { Knowledge Score } \text { S }_{i}=10-\sum_{k=1}^{K}\left|\log \left(E_{i k}\right)-\log \left(S_{k}\right)\right|
$$

$E_{i k}$ is the respondent $i^{\prime}$ s answer for question $k . K$ is the total number of questions, varying from four to six for different versions of the survey. Each question is weighted equally. $S_{k}$ is the standard (correct) answer for questions $k$. The difference between the logarithms of these two values was calculated. Logarithms allow the measurement of the difference in magnitude between two values rather than arriving at an exact number. The log differences for all questions were summed together and subtracted from 10 . This subtraction provided a positive knowledge score that represented the resource usage estimation accuracy. The larger the accumulated differences between estimates and standard answers, the lower the knowledge score; the closer the estimations to the standard answers, the higher the knowledge scores. The knowledge scores of different resource categories should not be compared to each other. 
Each answer in the environmental awareness questionnaire was coded from 1-5, with responses indicating the most positive attitude towards the environment receiving a score of 5 and the most negative attitude a score of 1 . Scores for the eight questions were added together to form a single "Awareness Score", varying from a minimum of 8 to a maximum of 40 . The higher the score, the more environmentally aware the respondent was assumed to be.

Median knowledge scores of each resource category were used to split respondents into a "higher knowledge" group and a "lower knowledge" group. Similarly, median awareness scores were used to split respondents into "higher awareness" and "lower awareness" groups. Preference models will be compared between these groups later to answer the second research question. We choose to use this median split method for its conceptual clarity.

\subsubsection{Design choice modeling}

Conditional logistic regression models were constructed to determine whether there were any relationships between design ratings and the respondents' choices of most preferred designs (McFadden, 1973; Train, 2002). The probability that the $\boldsymbol{i}^{\text {th }}$ design being chosen among the four designs of any product was:

$$
P_{i}=\frac{\exp \left(\beta \cdot X_{i}\right)}{\sum_{j=1}^{4} \exp \left(\beta \cdot X_{j}\right)}, \quad i=1,2,3,4
$$

where $X_{i}$ was a vector of averaged ratings of the evaluation criteria for design $i$, and $\beta$ was a vector of model coefficients. No intercept was included in the model for two reasons: first, design ratings were confounded with forms of design (Text or Chart designs on average had higher clarity ratings, and Metaphor Using Living Creatures designs in general had higher emotion ratings), thus estimating intercepts would cause the problem of collinearity; and second, each set of four designs was presented in random order, eliminating potential bias introduced by the presentation sequence.

Choice data from the four resource categories were pooled to construct the models. Ratings 
were normalized to range from $0-1$ before fitting to the model so that the model coefficients could be used directly to compare the importance of the explanatory variables. R package mlogit (Croissant, 2012) was utilized to estimate the model with maximum likelihood method.

\subsubsection{Investigating the Influence of Demographic Background.}

This study also noted how the demographic factors of the survey respondents might be related to their resource consumption knowledge, environmental awareness, and choices of designs. Because virtually all respondents were university students around a similar age, the analysis focused on the potential influence of country (US or Saudi Arabia) and gender of the survey respondents.

To understand the impact of the quantitative and the emotional aspects of a design on the selection of most preferred designs in different respondent groups, logistic regression models were fitted to the following groups respectively: female and male, higher and lower resource consumption knowledge groups, and higher and lower environmental awareness groups. To compare preferences between different groups of respondents, a two-tailed Z-test was used with a large sample assumption to compare the coefficients of different models (Clogg et al., 1995; Paternoster et al., 1998):

$$
Z=\frac{\left|\beta_{1}-\beta_{2}\right|}{\sqrt{S E \beta_{1}{ }^{2}+S E \beta_{2}{ }^{2}}}
$$

where $\beta_{1}$ and $\beta_{2}$ were the corresponding coefficients from model 1 and model 2 respectively, and the $S E \beta_{1}$ and $S E \beta_{2}$ were their standard errors. A significance level of 0.05 was selected. The two-tailed $p$-values were calculated as:

$$
p=2 \times[1-\Phi(Z)]
$$

where $\Phi(Z)$ is the cumulative normal distribution function of $Z$. 


\section{RESULTS}

\subsection{Study Participants}

The survey was distributed among undergraduate and graduate students at one US coeducational technology institute, one US women's liberal arts college, one all-male Saudi Arabian technology university, and two all-female Saudi Arabian universities. In total, 1018 surveys were initiated of which 658 were completed, corresponding to a $65 \%$ completion rate. After applying two screening rules, 619 valid responses (94\% of completed responses) remained. Table 1 summarizes the country and gender distribution of the valid responses.

The sample sizes in US and Saudi Arabia provided 5\% and 6\% margin of error, respectively, with $95 \%$ confidence level for enrolled university students in the two countries. The respondents formed a convenience sample that consisted of students from freshman to PhD and from various departments including science, engineering, social science, and arts, which covered a varied background. The proportion of female and male students were imbalanced, constrained by gender distributions of the surveyed university populations. However, sufficient data were collected in each group (the smallest group had 21 respondents), which allowed meaningful statistical comparison. The US respondents were allowed to provide their gender information as "self-identified", to align with recent gender identification efforts at some US university campuses. However, very few respondents reported "self-identified" gender, providing low power in statistical inference. Therefore, that data were not included in some of the analyses as noted below.

Table 1 Summary of valid survey responses

\begin{tabular}{cccccc}
\hline & Electricity & Material & Transportation & Water & Total \\
\hline \multirow{2}{*}{ Country A } & 81 & 111 & 80 & 99 & 371 \\
& $(\mathrm{~F}: 60, \mathrm{M}: 21)$ & $(\mathrm{F}: 77, \mathrm{M}: 32, \mathrm{~S}: 2)$ & $(\mathrm{F}: 51, \mathrm{M}: 27, \mathrm{~S}: 2)$ & $(\mathrm{F}: 73, \mathrm{M}: 26)$ & $(\mathrm{F}: 261, \mathrm{M}: 106, \mathrm{~S}: 4)$ \\
Country B & 61 & 60 & 62 & 65 & 248 \\
& $(\mathrm{~F}: 25, \mathrm{M}: 36)$ & $(\mathrm{F}: 28 \mathrm{M}: 32)$ & $(\mathrm{F}: 29, \mathrm{M}: 33)$ & $(\mathrm{F}: 24, \mathrm{M}: 41)$ & $(\mathrm{F}: 106, \mathrm{M}: 142)$
\end{tabular}


142

Total $\quad(\mathrm{F}: 85, \mathrm{M}: 57) \quad(\mathrm{F}: 105, \mathrm{M}: 64, \mathrm{~S}: 2) \quad(\mathrm{F}: 80, \mathrm{M}: 60, \mathrm{~S}: 2)$

164

619

Note: $\mathrm{F}$ - female, $\mathrm{M}$ - male, $\mathrm{S}$ - self-identified gender.

\subsection{Resource Consumption Knowledge Scores and Environmental Awareness Scores}

The means and the standard deviations of the knowledge scores for each resource category as well as the environmental awareness scores were calculated for each group of respondents of the same gender and country (see Figure 2). Higher knowledge scores represent a higher ability to estimate resource consumption. Not surprisingly, students from technical majors had higher knowledge scores overall compared to non-technical students (Bao et al., 2016). Higher awareness scores indicate higher environmental awareness. The data from the self-identified gender group were few and thus were not included.
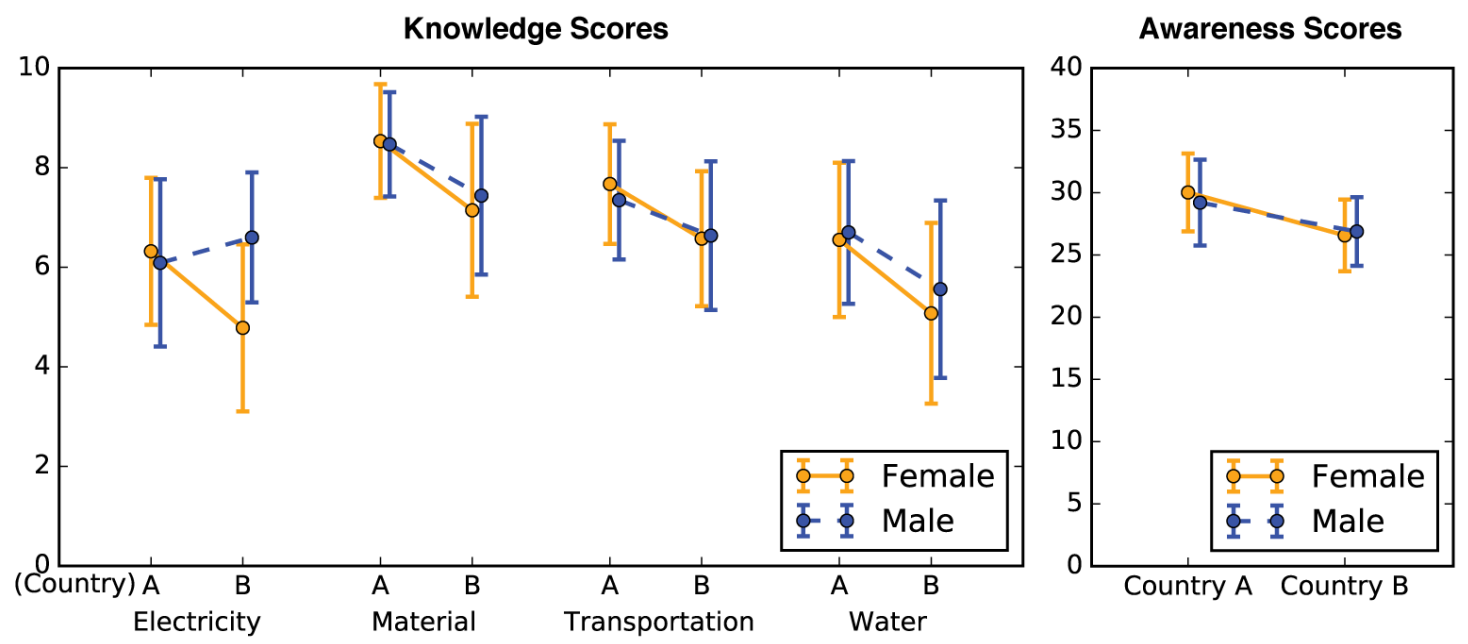

Figure 2 Distributions of knowledge scores and awareness scores by country and gender

Note: The dots and the error bars represent the average scores and the standard deviation of scores respectively from each group of respondents of same gender and country.

Two-way ANOVA (analysis of variance) was conducted to compare knowledge and awareness scores between countries and genders. The results are summarized in Table 2. No significant differences were detected between female and male respondents for knowledge scores in Material, Transportation, and Water category. However, respondents from country A 
had consistently higher knowledge scores for these three categories across both genders. The Electricity category was an exception: country B male respondents had significantly higher knowledge scores compared to country B female respondents regarding the electricity consumption. For the awareness scores, the interaction effect between country and gender was statistically significant at a 0.05 level. However, the effect of country was much more significant, indicating that the main difference in awareness scores was between countries rather than between genders. Overall, the differences in resource usage knowledge and environmental awareness scores were much more significant between the two countries, while gender had small or no differences regarding these two scores.

Table 2 Two-way ANOVA of knowledge scores and awareness scores between countries and genders

\begin{tabular}{cccccc}
\hline & \multicolumn{2}{c}{ Knowledge Scores } & Awareness \\
& Electricity & Material & Transportation & Water & Scores \\
\hline Country & 5.944 & 31.320 & 16.799 & 22.124 & 126.041 \\
& $\left(0.016^{*}\right)$ & $\left(<0.001^{* * *}\right)$ & $\left(<0.001^{* *}\right)$ & $\left(<0.001^{* * *}\right)$ & $\left(<0.001^{* * *}\right)$ \\
Gender & 7.826 & 0.132 & 0.406 & 1.141 & 1.420 \\
& $\left(0.006^{* *}\right)$ & $(0.717)$ & $(0.525)$ & $(0.287)$ & $(0.234)$ \\
Interaction & 14.029 & 0.652 & 0.722 & 0.357 & 4.598 \\
& $\left(<0.001^{* *}\right)$ & $(0.421)$ & $(0.397)$ & $(0.551)$ & $\left(0.032^{*}\right)$ \\
\hline
\end{tabular}

Note: Two-way ANOVA results significant on level of 0.05 are highlighted with light grey, $* p<0.05, * * p<0.01, * * * p<0.001$.

\subsection{Design Ratings}

The average clarity ratings and emotion ratings of each design are plotted in Figure 3 . As expected, more quantitative designs featuring Text or Chart had high clarity ratings but relatively low emotion ratings, presumably because they presented concise but dry information on resource usage. Some respondents liked such information as they commented: "it is interesting to see how consumption accumulates in a day", while the others were overwhelmed by the details as they pointed out that the Text or Chart designs have "too many words". In 
contrast, designs featuring Metaphor Using Living Creatures had high Emotion ratings but relatively low Clarity ratings, possibly because the images of animals and plants were evocative but lacked precision in presenting resource usage information. As respondents wrote: "animal figures have more emotional effect for raising awareness", "this design (with the whale image) makes you feel like you are saving a life". Designs with Visual Emphasis fell between these two, with relatively high ratings for both clarity and emotion as they are "simple and visual" and "quickly draw attention". Designs created by Metaphor Using Objects lie on the bottom left side of the figure, with lower ratings on average for both aspects. We found that the links between objects and the environment were less obvious than that between animals/plants and the environment. For example, respondents would not always associate a light bulb with energy conservation (E1) or a water bottle with water conservation (W1). Means and standard deviations of all four ratings of each design are summarized in the Supplementary Material.

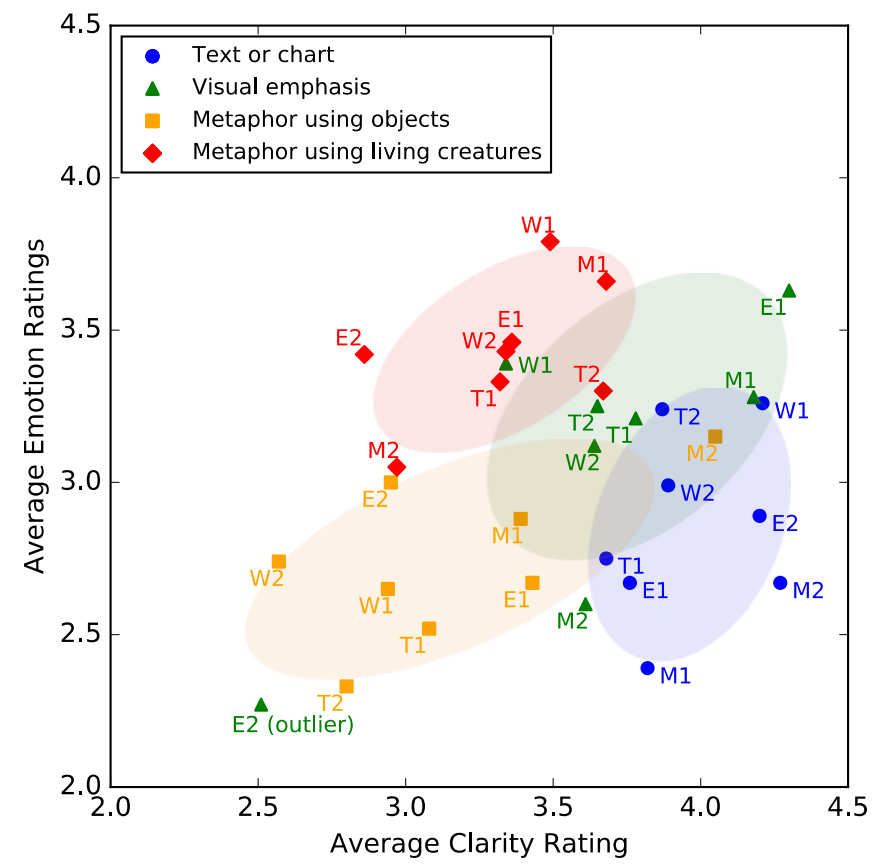

Figure 3 Average clarity and emotion ratings of the designs

Note: One data point represents the average ratings of one design; a shaded ellipse represents the mean and covariance of the average ratings of all products generated in one design form; the notation of E1, E2, etc. correspond to the designs as numbered in Supplementary Material. 
Large variances of the average ratings existed among products of the same form. Taking the electricity meter (E1) designs and the washing machine (W2) designs (shown in Figure 1) as examples, these two products in form of Visual Emphasis had noticeable differences in both clarity emotion ratings (as can be seen in Figure 3), presumably because the electricity meter design had many more visual elements, including a number representing accumulated electricity usage, a colored scale and an indicator of current usage, while the washing machine design only had colored buttons. In the scope of the current study, it would be hard to distinguish users' responses to the different visual elements on a single design.

Pearson correlation coefficients between the average ratings are summarized in Table 3. Effectiveness ratings were statistically significantly correlated with both Clarity and Emotion ratings; Appeal ratings were also correlated with Clarity and Emotion ratings. In addition, Effectiveness and Appeal ratings were highly correlated with each other. These results indicate that designs that presented clearer information and evoked stronger emotions were more likely to be perceived as effective in encouraging resource conservation behavior and were more likely to be perceived as appealing.

Table 3 Pearson correlation coefficients ( $p$-values) between average design ratings

\begin{tabular}{ccccc}
\hline & Clarity & Emotion & Effectiveness & Appeal \\
\hline Clarity & 1 & $0.310(0.085)$ & $0.733\left(<0.001^{* * *}\right)$ & $0.769\left(<0.001^{* * *}\right)$ \\
Emotion & - & 1 & $0.634\left(<0.001^{* * *}\right)$ & $0.715\left(<0.001^{* * *}\right)$ \\
Effectiveness & - & - & 1 & $0.921\left(<0.001^{* * *}\right)$ \\
Appeal & - & - & - & 1 \\
\hline
\end{tabular}

Note: ${ }^{*} p<0.05, * * p<0.01,{ }^{* * *} p<0.001$.

\subsection{Most Preferred Design Choices}

Overall, designs featuring Visual Emphasis were voted by the highest percentage of participants as "most preferred," followed by designs featuring Text or Chart and Metaphors 
Using Living Creatures. Figure 4 presents three designs that were voted as the "most preferred" by the majority or plurality of respondents. From left to right they are: an electricity meter design (E1) featuring Visual Emphasis, a paper towel dispenser design (M1) featuring Metaphor Using Living Creature, and a waste cans design (M2) featuring Text or Chart. They either had a high clarity rating (the waste cans) or high emotion rating (the paper towel dispenser), or both (the electricity meter). Figure 3Figure 3 can be referred to for the clarity and emotion ratings of these designs.
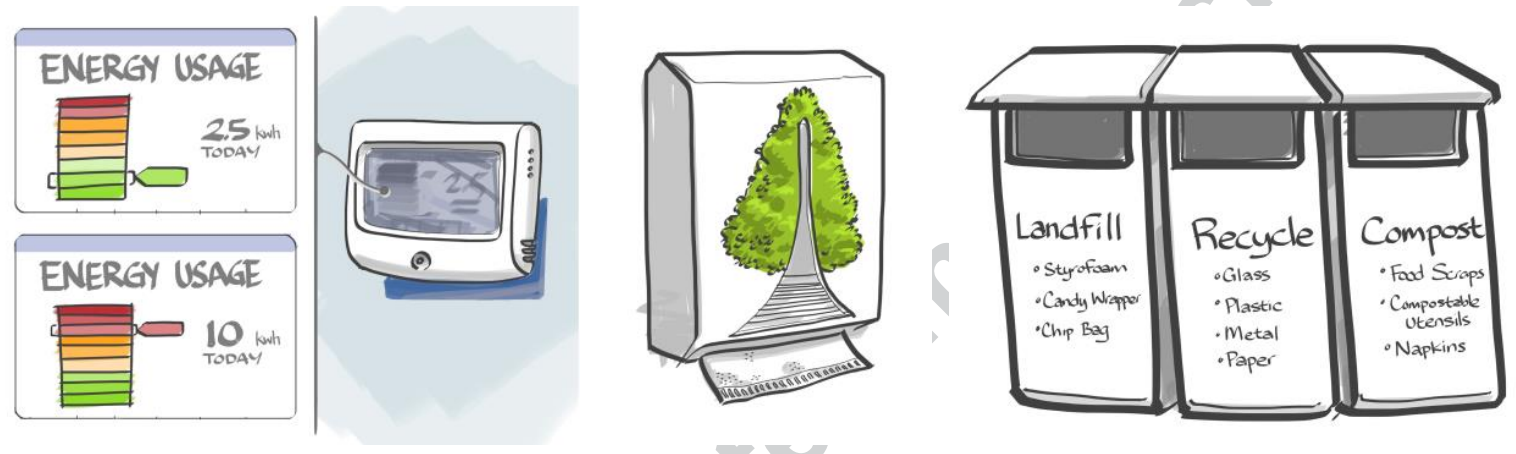

Figure 4 Example designs winning majority or plurality votes as the most preferred The left figure is reproduced with permission from ref (Bao et al., 2016), (c) 2016 ASME.

In the open ended comments section of the survey, some reported that they chose their most preferred design because it was "the most emotionally powerful", "the most evocative, and has the strongest emotional response"; while the others preferred to see more data and detailed information: "It's a lot clearer than the other", "It is the most informative and straightforward", "Considering resources (consumption) should be rational and practical, not emotional".

Logistic regression model as described in equation (2) was used to capture the relationship between the respondents' choices and the average ratings of evaluation criteria for each design. As similar trends were observed across the four resource categories, and creating choice models within each specific category would significantly reduce the sample sizes and 
thus the statistical power of the analysis, choice data from all participants (in total $\mathrm{N}=1238$ choices, two choices per respondent) was pooled to fit this model.

The average clarity and emotion ratings were included in the same choice models as explanatory variables. The effectiveness and appeal ratings were highly correlated with the clarity as well as with the emotion ratings as described in section 3.3 , and thus were excluded from this model to avoid collinearity. The coefficient for Clarity was $1.72 \pm 0.13$ (t-value $=$ 13.69, $p$-value $<0.001$ ) and the coefficient for Emotion was $1.30 \pm 0.14$ (t-value $=9.18, p$-value $<0.001$ ), both of which positive and statistically significant at a 0.05 level (model log-likelihood $=-1541.6)$. This confirmed that quantitative resource consumption information and emotional evocativeness both played important roles in influencing respondents' choices of their most preferred designs.

When the average effectiveness and the average appeal ratings were included in choice models on their own, their model coefficients were $3.15 \pm 0.17$ ( $\mathrm{t}$-value $=18.83, \mathrm{p}$-value $<$ $0.001)$ and $2.69 \pm 0.14(t-v a l u e=18.84, p$-value $<0.001)$, respectively, and their model loglikelihoods were -1499.3 and -1505 , respectively. Again, these coefficients were positive and statistically significant at a 0.05 level, showing the "most preferred" design choices also tended to be those rated as effective in encouraging sustainable behavior, and overall more appealing.

\subsection{Comparing Preferred Design Choices Between Demographic Groups}

This analysis focused on comparing respondents' reaction towards the quantitative and emotional aspects of the designs, and thus only included average clarity and emotion ratings as explanatory variables when comparing preferences between demographic groups. To eliminate potential confounding effects between knowledge scores, awareness scores, and countries (country A respondents had, on average, higher knowledge scores and higher awareness scores compared to country B, as discussed in section 3.2), logistic regression models were fitted to 
the higher and lower knowledge groups/awareness groups within each country. Higher and lower knowledge/awareness groups were constructed within each country using the median scores of that country. The preference models of females and males were also compared within each country to eliminate the potential bias induced by unbalanced sample sizes of different gender and country groups. Choice data for electricity-related products from Country B were excluded from the models to eliminate confounding between gender and knowledge scores. Comparisons of the model coefficients are summarized in Figure 5. Model coefficients are documented in Supplementary Material.
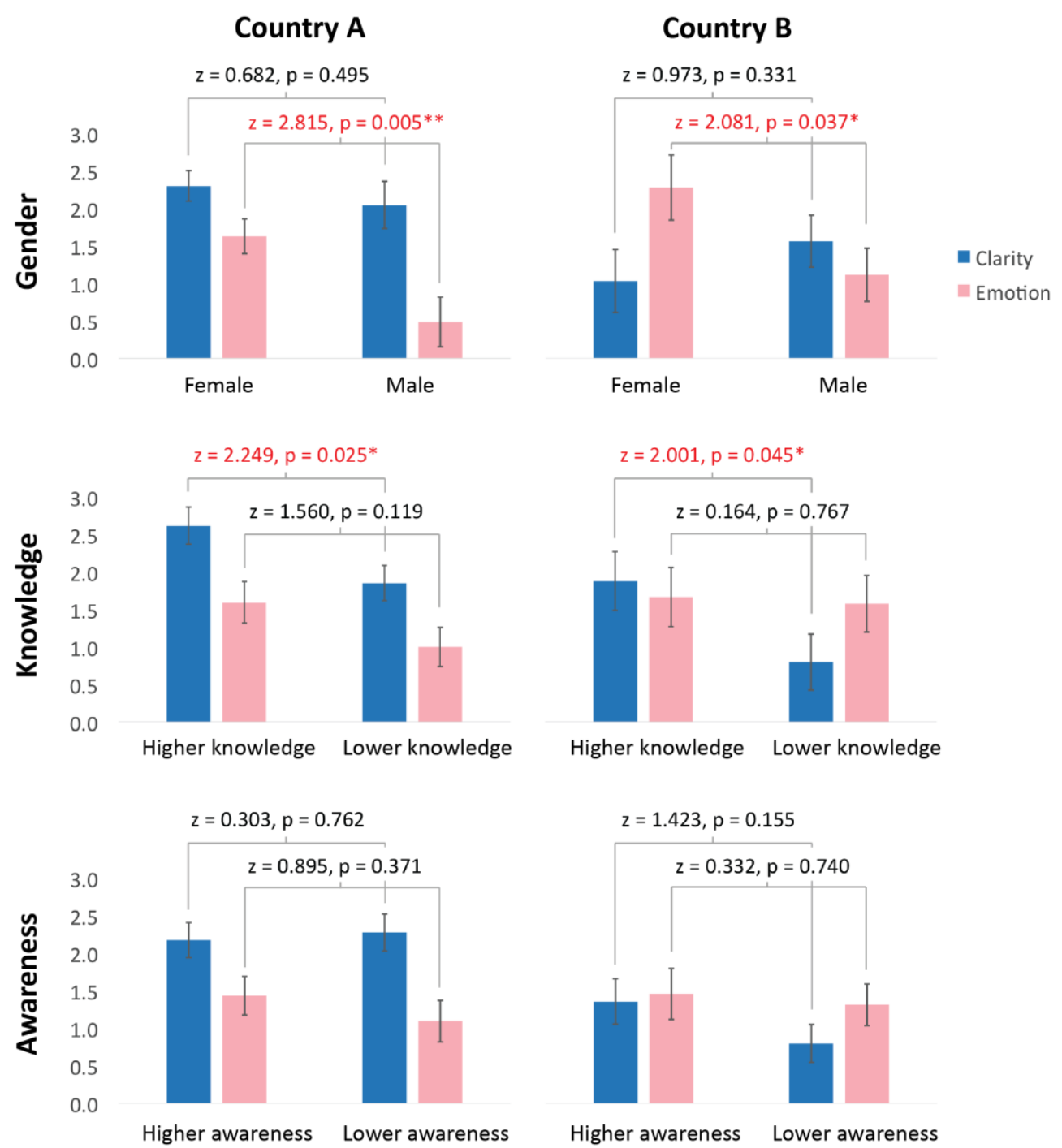
Figure 5 Comparison of logistic regression model coefficients between genders, higher and lower knowledge groups, higher and lower awareness groups within each country

Note: Blue bars and pink bars represent the estimated model coefficients of clarity ratings and emotion ratings respectively. Error bars represent the standard errors of coefficients. $Z$ statistics and $p$ values are calculated according to equations ( 3 ) and (4). ${ }^{*} p<0.05,{ }^{* *} p<0.01$, $* * * p<0.001$.

In both country A and country B, females had significantly higher emotion coefficients compared to males, while there were no significant differences between their clarity coefficients. Again in both countries, the higher knowledge groups (top 50\% knowledge scores) had significantly higher clarity coefficients, but not significantly different emotion coefficients, compared to the lower knowledge groups (bottom 50\% knowledge scores). Both clarity and emotion coefficients were not statistically different between the high awareness groups (top 50\% awareness scores) and the lower awareness groups (bottom $50 \%$ awareness scores). It would be interesting to investigate the impact of cultural differences between countries. However, in the data we collected, the country was confounded with knowledge score and gender (country A respondents had higher overall knowledge scores and a higher female to male ratio), which would likely bias the result. Therefore, direct comparison between countries was not conducted.

The differences between choice models of females and males suggested that the emotional aspect of a design had much more influence on female respondents' choices of most preferred designs than on male respondents. The quantitative aspect of a design appeared to be much more important to respondents who had higher resource consumption knowledge scores, indicating that respondents who were better at estimating resource consumption or possess more knowledge about resource consumption were more engaged with the quantitative resource usage data provided by the eco-feedback designs. 


\section{DISCUSSION}

Key findings regarding the original research questions are highlighted and discussed below, as well as the study limitations and directions for future work:

Q1: How are quantitative and emotionally evocative usage information presented in an ecofeedback design linked to users' evaluation of the design's appeal and users' perception of the design's effectiveness in encouraging sustainable behavior?

Traditional theoretical frameworks such as theory of reasoned action, theory of planned behavior, and value-belief-norm theory (Kollmuss and Agyeman, 2002; Oreg and Katz-gerro, 2006) were developed to predict pro-environmental behavior with people's environmental knowledge, and attitude. In addition, numerous empirical studies have explored the links between attitude, knowledge and behavior (Bradley et al., 1999; Meinhold and Malkus, 2005). Only recently have the impact of emotions on motivating sustainable behavior and moderating environmental belief and attitude gained attention (Bang et al., 2000; Carrus et al., 2008; Kim et al., 2013). Our study took a product-design perspective and investigated the presentation of resource usage information on products, with the emphasis not only on quantitative feedback but also on the emotional evocativeness of the information presented.

The results demonstrated that both quantitative resource usage information and emotional power of a design were important to the success of designs we evaluated, in the sense that designs with higher clarity ratings and higher emotion ratings tended to be rated as more appealing, more effective in encouraging sustainable behavior, and were more frequently chosen as the most preferred. This study did not examine the emotional valence or the specific type of emotions that were evoked by the designs. Different emotions may have different influences on user perception and preference (Lerner and Keltner, 2000). While positive emotions (such as satisfaction) could encourage users to be more involved with environmentally sustainable practices, negative emotions such as guilt might drive users away 
from further engagement with the products (MacDonald and She, 2015). A richer understanding of the types of emotions evoked by a design and their effectiveness in encouraging pro-environmental behaviors is an area ripe for further study (Bao et al., 2018).

In addition, the Effectiveness and Appeal ratings for designs were highly correlated. It may be that users were more attracted to designs they believed could spark environmentallyconscious behaviors; on the other hand, it is well known that designs that are more visually attractive are generally perceived to be more effective and work better (Kurosu and Kashimura, 1995; Tractinsky et al., 2000), regardless of whether they actually are. One limitation of this study is that the results were immediate user evaluations of designs. Gap between perceived effectiveness of a design and actual effectiveness of a product in promoting pro-environmental user behaviors likely exists. Also, stated design preference cannot be directly translated to market success as factors such as cost are not considered. Investigating consumers' willingnessto-buy with product prices considered; monitoring longer-term user-product interactions and investigating the designs' actual impact in encouraging sustainable behavior change, establishing habits, and changing values and beliefs concerning the environment would be exciting directions for future work.

Q2: Do users with different levels of environmental awareness or quantitative resource consumption knowledge, or with different demographic backgrounds respond differently to the quantitative and emotional aspects of resource usage information presented in an eco-feedback design?

The quantitative and the emotional aspects of resource usage information can influence users' thinking process, but in different ways. Quantitative usage might prompt users to think about their consumption in an logical and active manner known as system 2 thinking (Kahneman, 2011), and thus whether a user responds to it could largely depend on their ability 
to properly interpret the information (environmental knowledge) and their willingness to take the effort to interpret the information (environmental awareness). Not surprising, significant evidence was found that respondents with higher resource consumption knowledge scores were much more sensitive to the quantitative aspect of a design compared to respondents whose knowledge scores were lower. This illustrates a limitation of presenting merely quantitative resource usage information - to users who know little about resource consumption, the quantitative data might not be very attractive or informative, let alone encourage sustainable behaviors, just as calorie labeling of food does little for those who lack the understanding of calorie information (Bollinger et al., 2011; Elbel et al., 2009).

The emotional aspect, on the contrary, might prompt users to react in a faster and automatic manner (system 1 thinking). It was found that respondents were sensitive to the emotional aspect of designs to a similar degree, regardless of their resource consumption knowledge scores. This finding is useful as it provides guidelines to enlarge the impact of ecodesigns by emotionally engaging a broader audience of users, including those who don't possess much quantitative knowledge about resource consumption. In addition, female respondents were found to be more sensitive to the emotional aspects of the design than male respondents, consistent with empirical evidence that women generally respond more emotionally to visual stimuli than men (Grossman and Wood, 1993). This finding can help form principles for designing compelling eco-feedback products for specific genders.

Contrary to our expectation, no significant difference in design preferences was found between respondents with higher or lower environmental awareness scores. The environmental awareness evaluation questions in this study were built upon existing measures of pro-environmental attitude (Attari et al., 2016; Dunlap et al., 2000). However, self-reported environmental awareness can be subjective, and validations of the measurements should be conducted in future work. 
We believe the four categories (electricity, material, transportation, and water) explored in the study covered a large enough range of resources and environment-related fields to provide generalizable results. However, the eco-feedback strategy presented could be applied to other categories, such as encouraging a low-carbon diet (De Boer et al., 2016) or reducing food waste (Venkat, 2011). In this study, design evaluation was collected from university students. Though the students we surveyed covered a large variety of demographic backgrounds, in future studies, it would be beneficial to conduct the study with participants that are not limited to the student population.

Four forms of designs were investigated in this study. Visual Emphasis was shown to be an effective design form. On average, this type of design had the highest ratings on both clarity and emotion and tended to receive more votes as the most preferred designs. Meanwhile, Text or Chart and Metaphor Using Living Creatures were demonstrated to be the most quantitative and the most emotionally evocative design forms, respectively. However, it should be noted that the forms of design were intentionally isolated in this study so that their influence could be examined separately. In addition, the survey participants were evaluating each design holistically. In practice, designers should not be obligated to follow a single form of design. Instead, they should adjust, combine, or create new design forms as needed. Other forms of design and ways of presenting resource usage information that are worthy of study, includes setting goals for resource conservation (Abrahamse et al., 2007) or gamifying the resource conservation process (Gustafsson et al., 2009).

\section{CONCLUSIONS}

This study investigated an eco-design strategy known as eco-feedback design. This strategy explicitly presents product resource consumption information as a way of encouraging 
sustainable product use. The stance of the work was consistent with other research that investigates the social and psychological aspects of eco-design implementation (Boks, 2006; MacDonald and She, 2015), and bridged the gap between the technical aspects of eco-design development (Rounds and Cooper, 2002) and interventions for promoting resource conservation behavior (Nahiduzzaman et al., 2018).

This work focuses on evaluating different design forms and their impact on user perceptions of designs. It contributed to the rich literature of eco-design by presenting an experimental and evidence-based approach that elicits user feedback for conceptual designs in the early stage of product design and development. We evaluated how users perceive thirty-two intervention designs of household products in four resource categories, including electricity, water, materials, and transportation. Four design forms were explored, covering a range from quantitative to emotionally evocative. We mapped the designs to a 2D space of quantitative and emotional, and demonstrated that both the quantitative and emotional power of a design were important to the success of these products in the sense that designs rated to show clearer resource usage information and evoke stronger emotions tended to be rated as more appealing, perceived as more effective in encouraging sustainable behavior, and more frequently chosen as the most preferred designs. In addition, we found significant preference differences concerning the quantitative and emotional aspects of resource usage information between respondents with different resource consumption knowledge scores and between male and female respondents, respectively.

These findings challenge the traditional strategies of designing eco-feedback products whose single focus was on presenting quantitative information and point to the direction of creating designs that can better engage users emotionally. The four specific design forms investigated in the study have implications for ways of designing and developing these products in practice. In addition, the methods established in this study that collect user feedback on 
provisional design representations could be used by designers to accelerate the development of all kinds of sustainable products.

\section{ACKNOWLEDGEMENTS}

The authors would like to thank Dr. Areej Al-Wabill, Dr. Asmaa Elantary, Dr. Malak Al-Noury and Dr. Muhammad Asif for their expert input, and Nathan Cooke for his excellent sketching skills. The work was supported in part by the Center for Clean Water and Clean Energy at MIT and KFUPM (King Fahd University of Petroleum and Minerals in Dhahran, Saudi Arabia). This work was also supported in part by Singapore University of Technology and Design (SUTD) - MIT graduate Fellowship. The opinions, findings, and conclusions expressed are those of the authors and do not necessarily reflect the views of the sponsors.

\section{REFERENCE}

Abrahamse, W., Steg, L., Vlek, C., Rothengatter, T., 2007. The effect of tailored information, goal setting, and tailored feedback on household energy use, energy-related behaviors, and behavioral antecedents. Journal of Environmental Psychology 27, 265-276.

Agarwal, Y., Weng, T., 2009. The energy dashboard: Improving the visibility of energy consumption at a campuswide scale, in: Proceedings of the First ACM Workshop on Embedded Sensing Systems for Energy-Efficiency in Buildings. ACM, 2009. Berkeley, California, pp. 55-60. https://doi.org/10.1145/1810279.1810292

Aldrovandi, S., Brown, G.D.A., Wood, A.M., 2015. Social norms and rank-based nudging: Changing willingness to pay for healthy food. Journal of Experimental Psychology: Applied 21, 242.

Arroyo, E., Bonanni, L., Selker, T., 2005. Waterbot: Exploring feedback and persuasive techniques at the sink, in: $\mathrm{CHI}$ '05 Proceedings of the SIGCHI Conference on Human Factors in Computing Systems. Portland, OR, pp. 631-639. https://doi.org/10.1145/1054972.1055059

Attari, S.Z., Dekay, M.L., Davidson, C.I., Bruine, W., Bruin, D., 2010. Public perceptions of energy consumption and savings. Proceedings of the National Academy of Sciences 107, 16054-16059. https://doi.org/10.1073/pnas.1001509107//DCSupplemental.www.pnas.org/cgi/doi/10.1073/pnas.1001509107

Attari, S.Z., Krantz, D.H., Weber, E.U., 2016. Energy conservation goals: What people adopt, what they recommend, and why. Judgement and Decision Making 11, 342-351.

Bang, H., Ellinger, A.E., Hadjimarcou, J., Traichal, P.A., 2000. Consumer concern, knowledge, belief, and attitude toward renewable energy: An application of the reasoned action theory. Psychology \& Marketing 17, 449468. 
Bao, Q., Hughes, A., Burnell, E., Yang, M.C., 2018. Investigating User Emotional Responses to Eco-Feedback Designs, in: ASME 2018 International Design Engineering Technical Conferences and Computers and Information in Engineering Conference. Quebec City, Canada.

Bao, Q., Shaukat, M.M., Elantary, A., Yang, M.C., 2016. Eco-Feedback Designs: A Balance between the Quantitative and the Emotional, in: ASME 2016 International Design Engineering Technical Conferences. Charlotte, NC, pp. 1-12.

Barreto, M., Karapanos, E., Nunes, N., 2013. Why don't families get along with eco-feedback technologies?: a longitudinal inquiry, in: Proceedings of the Biannual Conference of the Italian Chapter of SIGCHI. ACM, p. 16.

Bhamra, T., Lilley, D., Tang, T., 2008. Sustainable use: Changing consumer behaviour through product design, in: Changing the Change: Design Visions, Proposals and Tools. Turin, Italy.

Boatwright, P., Cagan, J., 2010. Built to Love: Creating Products that Captivate Customers. Berrett-Koehler Publishers.

Boks, C., 2006. The soft side of ecodesign. Journal of Cleaner Production 14, 1346-1356.

Bollinger, B., Leslie, P., Sorensen, A., 2011. Calorie posting in chain restaurants. American Economic Journal: Economic Policy 3, 91-128.

Boudet, H., Ardoin, N.M., Flora, J., Armel, K.C., Desai, M., Robinson, T.N., 2016. Effects of a behaviour change intervention for Girl Scouts on child and parent energy-saving behaviours. Nature Energy 1, 16091. https://doi.org/10.1038/nenergy.2016.91

Bradley, J.C., Waliczek, T.M., Zajicek, J.M., 1999. Relationship between environmental knowledge and environmental attitude of high school students. The Journal of Environmental Education 30, 17-21.

Carrus, G., Passafaro, P., Bonnes, M., 2008. Emotions, habits and rational choices in ecological behaviours: The case of recycling and use of public transportation. Journal of Environmental Psychology 28, 51-62.

Clogg, C.C., Petkova, E.P., Haritou, A., 1995. Statistical methods for comparing regression coefficients between models. American Journal of Sociology 100, 1261-1293.

Cor, E., Zwolinski, P., 2015. A protocol to address user behavior in the eco-design of consumer products. Journal of Mechanical Design 137. https://doi.org/10.1115/1.4030048

Croissant, Y., 2012. Estimation of multinomial logit models in R: The mlogit Packages. R package version 0.2-2.

D'Souza, C., Taghian, M., Lamb, P., Peretiatko, R., 2007. Green decisions: Demographics and consumer understanding of environmental labels. International Journal of Consumer Studies 31, 371-376.

Daae, J., Boks, C., 2015. A classification of user research methods for design for sustainable behaviour. Journal of Cleaner Production 106, 680-689.

De Boer, J., De Witt, A., Aiking, H., 2016. Help the climate, change your diet: A cross-sectional study on how to involve consumers in a transition to a low-carbon society. Appetite 98, 19-27.

Deutz, P., Neighbour, G., McGuire, M., 2010. Integrating sustainable waste management into product design: Sustainability as a functional requirement. Sustainable Development 18, 229-239. https://doi.org/10.1002/sd.469

Diego-Mas, J.-A., Poveda-Bautista, R., Alcaide-Marzal, J., 2016. Designing the appearance of environmentally sustainable products. Journal of Cleaner Production 135, 784-793.

Dunlap, R.E., Van Liere, K.D., Mertig, A.G., Jones, R.E., 2000. Measuring endorsement of the New Ecological Paradigm: A revised NEP scale. Journal of Social Issues 56, 425-442. https://doi.org/10.1111/00224537.00176

Elbel, B., Kersh, R., Brescoll, V.L., Dixon, L.B., 2009. Calorie labeling and food choices: A first look at the effects on low-income people in New York City. Health Affairs 28, w1110-w1121. 
Fang, W., Hsu, J., 2010. Design concerns of persuasive feedback system. Visual Representations and Reasoning 2025.

Feick, L.F., Higie, R. a., 1992. The effects of preference heterogeneity and source characteristics on ad processing and judgments about endorsers. Journal of Advertising 21, 9-24. https://doi.org/10.1080/00913367.1992.10673364

Fielding, K.S., Spinks, A., Russell, S., McCrea, R., Stewart, R., Gardner, J., 2013. An experimental test of voluntary strategies to promote urban water demand management. Journal of Environmental Management 114, 343351. https://doi.org/10.1016/j.jenvman.2012.10.027

Finnveden, G., Hauschild, M.Z., Ekvall, T., Guinee, J., Heijungs, R., Hellweg, S., Koehler, A., Pennington, D., Suh, S., 2009. Recent developments in Life Cycle Assessment. Journal of Environmental Management 91, 1-21. https://doi.org/10.1016/j.jenvman.2009.06.018

Fishkin, K.P., 2004. A taxonomy for and analysis of tangible interfaces. Personal and Ubiquitous Computing 8, 347358. https://doi.org/10.1007/s00779-004-0297-4

Frank, R.H., Glass, A.J., 1991. Rational consumer choice, in: Microeconomics and Behavior. McGraw-Hill New York.

Froehlich, J., Findlater, L., Landay, J., 2010. The design of eco-feedback technology. Proceedings of the 28th International Conference on Human Factors in Computing Systems 1999-2008. https://doi.org/10.1145/1753326.1753629

Froehlich, J., Findlater, L., Ostergren, M., Ramanathan, S., Peterson, J., Wragg, I., Larson, E., Fu, F., Bai, M., Patel, S., Landay, J. a, 2012. The design and evaluation of prototype eco-feedback displays for fixture-level water usage data, in: $\mathrm{CHI}$ '12 Proceedings of the SIGCHI Conference on Human Factors in Computing Systems. Austin, Texas, pp. 2367-2376. https://doi.org/10.1145/2207676.2208397

Galitz, W.O., 2007. The Essential Guide to User Interface Design: An Introduction to GUI Design Principles and Techniques. John Wiley \& Sons.

Goucher-Lambert, K., Cagan, J., 2015. The impact of sustainability on consumer preference judgments of product attributes. Journal of Mechanical Design 137, 081401. https://doi.org/10.1115/1.4030271

Goucher-Lambert, K., Moss, J., Cagan, J., 2017. A meta-analytic approach for uncovering neural activation patterns of sustainable product preference decisions, in: Design Computing and Cognition'16. Springer, pp. 173-191.

Grossman, M., Wood, W., 1993. Sex differences in intensity of emotional experience: A social role interpretation. Journal of Personality and Social Psychology 65, 1010.

Gustafsson, A., Katzeff, C., Bang, M., 2009. Evaluation of a pervasive game for domestic energy engagement among teenagers. Computers in Entertainment (CIE) 7, 54.

Häggman, A., Tsai, G., Elsen, C., Honda, T., Yang, M.C., 2015. Connections between the design tool, design attributes, and user preferences in early stage design. Journal of Mechanical Design 137. https://doi.org/10.1115/1.4030181

Järvi, P., Paloviita, A., 2007. Product-related information for sustainable use of laundry detergents in Finnish households. Journal of Cleaner Production 15, 681-689.

Kahneman, D., 2011. Thinking, Fast and Slow. Farrar, Straus and Giroux New York.

Karlsson, R., Luttropp, C., 2006. EcoDesign: What's happening? An overview of the subject area of EcoDesign and of the papers in this special issue. Journal of Cleaner Production 14, 1291-1298.

Kim, Y.J., Njite, D., Hancer, M., 2013. Anticipated emotion in consumers' intentions to select eco-friendly restaurants: Augmenting the theory of planned behavior. International Journal of Hospitality Management 34, 255-262.

Kittur, A., Chi, E.H., Suh, B., 2008. Crowdsourcing user studies with Mechanical Turk, in: CHI '08 Proceedings of the SIGCHI Conference on Human Factors in Computing Systems. Florence, Italy, pp. 453-456. 
Kobayashi, H., 2005. Strategic evolution of eco-products: a product life cycle planning methodology. Research in Engineering Design 16, 1-16.

Kollmuss, A., Agyeman, J., 2002. Mind the Gap: Why do people act environmentally and what are the barriers to pro-environmental behavior? Environmental Education Research 8. https://doi.org/10.1080/1350462022014540

Kroll, E., Hanft, T.A., 1998. Quantitative evaluation of product disassembly for recycling. Research in engineering design 10, 1-14.

Kurosu, M., Kashimura, K., 1995. Apparent usability vs. inherent usability: Experimental analysis on the determinants of the apparent usability, in: $\mathrm{CHI}$ '95 Conference Companion on Human Factors in Computing Systems. ACM, Denver, Colorado, pp. 292-293.

Kurz, T., Donaghue, N., Walker, I., 2005. Utilizing a social-ecological framework to promote water and energy conservation: A field experiment. Journal of Applied Social Psychology 35, 1281-1300. https://doi.org/10.1111/j.1559-1816.2005.tb02171.x

Kuznetsov, S., Paulos, E., 2010. UpStream: Motivating water conservation with low-cost water flow sensing and persuasive displays, in: $\mathrm{CHI}$ '10 Proceedings of the SIGCHI Conference on Human Factors in Computing Systems. Atlanta, GA, pp. 1851-1860. https://doi.org/10.1145/1753326.1753604

Lerner, J.S., Keltner, D., 2000. Beyond valence: Toward a model of emotion-specific influences on judgement and choice. Cognition \& Emotion 14, 473-493.

Lilley, D., 2009. Design for sustainable behaviour: strategies and perceptions. Design Studies 30, 704-720. https://doi.org/10.1016/j.destud.2009.05.001

Lilley, D., Lofthouse, V., Bhamra, T., 2005. Towards instinctive sustainable product use, in: International Conference in Sustainability, Creating the Culture. pp. 2-4.

Luce, R.D., 2005. Individual Choice Behavior: A Theoretical Analysis. Courier Corporation.

MacDonald, E.F., She, J., 2015. Seven cognitive concepts for successful eco-design. Journal of Cleaner Production 92, 23-36.

MacDonald, E.F., She, J., 2013. Trigger features on prototypes increase preference for sustainability, in: ASME 2013 International Design Engineering Technical Conferences and Computers and Information in Engineering Conference. Portland, Oregon. https://doi.org/10.1115/DETC2013-12973

Macomber, B., Yang, M., 2011. The role of sketch finish and style in user responses to early stage design concepts, in: ASME 2011 International Design Engineering Technical Conferences and Computers and Information in Engineering Conference. Washington, DC, USA, pp. 567-576. https://doi.org/10.1115/DETC2011-48714

Mason, W., Suri, S., 2012. Conducting behavioral research on Amazon's Mechanical Turk. Behavior Research Methods 44, 1-23.

McCalley, L.T., Midden, C.J.H., 2002. Energy conservation through product-integrated feedback: The roles of goalsetting and social orientation. Journal of Economic Psychology 23, 589-603. https://doi.org/10.1016/S01674870(02)00119-8

McCalley, L.T., Midden, C.J.H., 1998. Computer based systems in household appliances: The study of eco-feedback as a tool for increasing conservation behavior, in: 3rd Asia Pacific Computer Human Interaction. IEEE, pp. 18. https://doi.org/10.1109/APCHI.1998.704455

McFadden, D., 2001. Economic choices. The American Economic Review 91, 351-378.

McFadden, D., 1973. Conditional logit analysis of qualitative choice behavior. Frontiers in Econometrics 105-142.

McKenzie-Mohr, D., 2000. Fostering sustainable behavior through community-based social marketing. The American Psychologist 55, 531-537. https://doi.org/10.1037/0003-066X.55.5.531 
Meinhold, J.L., Malkus, A.J., 2005. Adolescent environmental behaviors: Can knowledge, attitudes, and self-efficacy make a difference? Environment and Behavior 37, 511-532.

Mesa, J., Maury, H., Arrieta, R., Corredor, L., Bris, J., 2018. A novel approach to include sustainability concepts in classical DFMA methodology for sheet metal enclosure devices. Research in Engineering Design 29, $227-244$.

Montazeri, S., 2013. Design for behavior change: The role of product visual aesthetics in promoting sustainable behavior. University of Michigan.

Montazeri, S., Finkbiner, D., Papalambros, P., Gonzalez, R., 2013. Save a napkin, save a tree: The role of metaphors in product design to change behavior, in: International Conference On Engineering Design, Design for Harmonies. Seoul, Korea, pp. 1-10.

Montazeri, S., Gonzalez, R.D., Yoon, C., Papalambros, P.Y., 2012. Color, cognition, and recycling: How the design of everyday objects prompt behavior change, in: Proceedings of International Design Conference.

Nahiduzzaman, K.M., Aldosary, A.S., Abdallah, A.S., Asif, M., Kua, H.W., Alqadhib, A.M., 2018. Households energy conservation in Saudi Arabia: Lessons learnt from change-agents driven interventions program. Journal of Cleaner Production 185, 998-1014.

Norman, D., 2013. The Design of Everyday Things. Basic Books (AZ).

Norman, D.A., 2004. Emotional Design: Why We Love (or Hate) Everyday Things. Basic Civitas Books.

Oreg, S., Katz-gerro, T., 2006. Predicting proenvironmental behavior cross-nationally: Values, the theory of planned behavior, and value-belief-norm theory. Environment and Behavior 38, 462-483. https://doi.org/10.1177/0013916505286012

Paternoster, R., Brame, R., Mazerolle, P., Piquero, A., 1998. Using the correct statistical test for the equality of regression coefficients. Criminology 36, 859-866. https://doi.org/10.1111/j.1745-9125.1998.tb01268.x

Petersen, D., Steele, J., Wilkerson, J., 2009. WattBot: A residential electricity monitoring and feedback system, in: CHI '09 Extended Abstracts on Human Factors in Computing Systems. Boston, MA, p. 2847. https://doi.org/10.1145/1520340.1520413

Rodriguez, E., Boks, C., 2005. How design of products affects user behaviour and vice versa: The environmental implications, in: 4th International Symposium on Environmentally Conscious Design and Inverse Manufacturing. IEEE, Tokyo, Japan, pp. 54-61. https://doi.org/10.1109/ECODIM.2005.1619166

Rose, C.M., Ishii, K., Stevels, A., 2002. Influencing design to improve product end-of-life stage. Research in Engineering Design 13, 83-93.

Rounds, K.S., Cooper, J.S., 2002. Development of product design requirements using taxonomies of environmental issues. Research in Engineering Design 13, 94-108.

Shu, L.H., Du, J., Herrmann, C., Sakao, T., Shimomura, Y., Bock, Y. De, Srivastava, J., 2017. Design for reduced resource consumption during the use phase of products. CIRP Annals 66, 635-658.

Sohn, M., Nam, T., 2015. Understanding the attributes of product intervention for the promotion of proenvironmental behavior: A framework and its effect on immediate user reactions. International Journal of Design 9, 55-77.

Srivastava, J., Shu, L.H., 2015. Considering different motivations in design for consumer-behavior change, in: ASME 2015 International Design Engineering Technical Conferences and Computers and Information in Engineering Conference. Boston, MA.

Staats, H., Harland, P., Wilke, H.A.M., 2004. Effecting durable change: A team approach to improve environmental behavior in the household. Environment and Behavior 36, 341-367. https://doi.org/10.1177/0013916503260163

Swim, J.K., Bloodhart, B., 2015. Portraying the perils to polar bears: The role of empathic and objective perspective-taking toward animals in climate change communication. Environmental Communication 9, 446- 
468.

Tang, T., Bhamra, T., 2008. Changing energy consumption behaviour through sustainable product design, in: Proceedings DESIGN 2008, the 10th International Design Conference. Dubrovnik, Croatia, pp. 1359-1366. https://doi.org/9789536313891

Telenko, C., Seepersad, C.C., 2010. A Methodology for Identifying Environmentally Conscious Guidelines for Product Design. Journal of Mechanical Design 132, 091009. https://doi.org/10.1115/1.4002145

Telenko, C., Seepersad, C.C., Webber, M.E., 2008. A compilation of design for environment principles and guidelines, in: ASME 2008 International Design Engineering Technical Conferences and Computers and Information in Engineering Conference. Brooklyn, New York, pp. 289-301.

Tractinsky, N., Katz, A.S., Ikar, D., 2000. What is beautiful is usable. Interacting with Computers 13, 127-145.

Train, K.E., 2002. Discrete Choice Methods With Simulation, Cambridge University Press. Cambridge University Press.

Ueno, T., Sano, F., Saeki, O., Tsuji, K., 2006. Effectiveness of an energy-consumption information system on energy savings in residential houses based on monitored data. Applied Energy 83, 166-183.

Venkat, K., 2011. The climate change and economic impacts of food waste in the United States. International Journal on Food System Dynamics 2, 431-446.

Wever, R., 2003. Influence of packaging design on littering behavior. Packaging Technology and Science 23, 239252.

Wever, R., van Kujik, J., Boks, C., 2008. User-centred design for sustainable behaviour. International Journal of Sustainable Engineering 1, 9-20. https://doi.org/10.1080/19397030802166205

Windrum, P., Ciarli, T., Birchenhall, C., 2009. Environmental impact, quality, and price: Consumer trade-offs and the development of environmentally friendly technologies. Technological Forecasting and Social Change 76, 552-566. https://doi.org/10.1016/j.techfore.2008.04.012

Zachrisson, J., Boks, C., 2012. Exploring behavioural psychology to support design for sustainable behaviour research. Journal of Design Research 10,50-66. https://doi.org/10.1080/10643389.2012.728825 